\title{
Cultural Analysis of the Rural Education in China
}

\author{
Lang Yongqing \\ Dept. of Humanities and Social Sciences, Beijing Electronic Science and Technology Institute, Beijing, China \\ lance@besti.edu.cn
}

\begin{abstract}
This article analyzes the rural education in China in the perspective of culture. Rural education is regarded as a cultural product. Social justice, social class, habitus and literacy are the main cultural elements, which are used to probe the problems of rural education in China. And then, the article suggests several strategies for addressing the problems. Basically, we need to increase financial input to the underdeveloped rural areas. However, what is important is to reform the funding assurance system for compulsory education in the countryside, thus bringing rural compulsory education expenditure into the overall public funding assurance framework.

Index terms - cultural products, habitus, social class, social justice, strategies
\end{abstract}

\section{I . Introduction}

China's 9 million farmers make up $2 / 3$ of China's total population. According to statistics, there are more than 80 thousand primary schools and middle schools in China, most of which are in rural areas. Moreover, the number of primary and middle school students takes up 3 quarters of the whole. The main tasks of rural schools are to provide formal education to the young generation as well as non-formal education to raise the literacy level of rural population. The functions should be fully played to meet the needs of local farmers in the development of actual production and the improvement of living standards. During the transition process from traditional agriculture production to modernized agriculture, the farmer are in urgent needs to master both literacy skills and scientific knowledge, which give rise to the higher requirements for all kinds of schools in rural areas.

However, due to a variety of historical and economic reasons, there are a lot of problems in rural education in China. Quality of education and success of students are directly related to the economic situation of the locality. Elementary and junior middle schools are directly funded by local taxes. China suffers from economic divides at different levels: between western/northern and eastern/southern provinces, within provinces between cities and countryside, and within towns and villages between rich and poor people. Lack of money affects the countryside in many ways: schools cannot afford good teachers, small classes, good teaching materials, and maintenance of the buildings. Moreover, if the town or village is poor, parents will more often want their child to go work rather than pursue further education. In rural areas, senior high school students constitute only $20 \%$ of their age group, while this is $70 \%$ in cities. (Wei Ji Ma, 2004). What's more, rural areas are generally more backward in their teaching methods than cities. For instance, it is normal that students just sit in class listening and obeying, without actively participating or asking questions. Teamwork, student projects, debating, and exploring your own interests are practically unheard of in Chinese education. (Wei Ji Ma, 2004)

Rural development is a matter of urgent concern in China, given its crucial role in national modernization and the stubborn pertinacity of its problems. This concern is reflected in more than 30 studies of rural education published in Educational Research, China's premier educational research journal (Hubert, 1986).

\section{The rural education is a cultural product.}

According to Ben Wadham, cultural products are artifacts produced and interpreted or used by people - they may be ideas, words, books, lectures, poems, bodily movements and movies - the list is endless. The production of all cultural products takes place in particular contexts. The political context, the religious context, the economic context and the cultural contest all shape and influence how a product is produced and why it is produced.(Ben, 2007).

Let's take the rural education in China as an example; surely it was produced in political and economic context. There is a lot of migration to cities (there are an estimated 100 million migrants, including teachers in countryside), which hampers the development of the rural areas. Migrants have few social and economic rights, because of the system of hu kou (birthplace rights). This system is dysfunctional and unfair, and it is slowly being abolished. Many migrants end up uneducated and unqualified, which is an increasing problem. Even rural students who have graduated from college sometimes have to go back to their hometown because of hu kou. (Wei Ji Ma, 2004) There are more factors which put rural students at a disadvantage. Although students from any province have a chance to be admitted to any university, admission chances are unfairly distributed. Many poor provinces get low quota, so students have to work harder to enter a good university and this often with less good of a basic education. Beijing and Shanghai are disproportionately favored, mainly because there are so many top universities there.

In China, education is central to culture and society. It has therefore been greatly influenced by the economic and social changes of the last decade. While China's economy is closely watched by the rest of the world, it is often forgotten that education is the long-term engine behind economic development. In the realm of education, rural areas form the bottleneck of development. Not only is the gap between poor rural areas and cities already large, many rural areas also hardly benefit from the country's overall economic growth. (Wei Ji Ma, 2004) 
When we are analyzing a cultural product, we shall ask questions such as "Who is involved? What is being said or done? Why is this a concern? Therefore, when we analyze rural education in China, we know it involves the rural school children, teachers, parents and the governments.

For decades, the Chinese government and other charities have been offering material support to rural education in the form of schools, scholarships, and equipment. However, the vast majority of rural children still drop out during or immediately after junior middle school, in stark contrast to urban areas where most children finish high school. Only a small minority of rural children (less than $20 \%$ ) go on to high school and the rest become farmers or migrant laborers. In most rural areas economic factors are no longer the main reason for dropping out. Instead, low scores in the examcentered system, lack of educational engagement, and lack of relevance to life are major reasons why students choose not to continue their education.

This brings up the question: "How effective is rural education?" How well does education impart knowledge and practical skills that are useful to students' future lives? The current exam-centered system drills basic literacy and math skills, but does not do enough to develop life-relevant knowledge and thinking skills. Instead of encouraging students to analyze problems and design solutions, it stifles creativity, independent thinking, and self-esteem. We have heard these complaints from many rural teachers :(rural china Education Foundation, http://www.ruralchina.org)

\section{A. Social justice}

Social justice is one of the most under-defined, undertheorized and capricious concepts. (Karen, 1991). Karen Starr presented three generalized "positions" on social justice: they are the conservative view, liberal view and socialist view of social justice. The conservative view accepts that there will be social inequalities, but that to be given a fair go, there should be "equal opportunities". Liberal view defines social justice as "fairness" and possible to achieve within our current social and political structures. Its strategies aim to overcome prejudice and to redress the marginalization of individuals and groups from mainstream discourse; Socialist view of social justice in education means giving students the skills to be fully active in society. It means participatory decision making, It means getting involved with learning projects that can have political and tangible outcomes (Karen, 1991) .

Although China is now marching towards the all-around, well-off society, at the same time, urban and rural developments began to lose their balance seriously: Rural development has lagged far behind that of the cities, especially in education. The gap between urban and rural compulsory education is so tremendous that it has already exceeded that of the economy (Bao Chuanyou , 2006). The gap covers the education funds, teacher's level of education and enrollment opportunities. For example, chances for obtaining higher education are three to four times larger for urban than for rural students (source: Dr. Hong Wei, An empirical study on opportunity equality between urban and rural higher education in China).

The sticking point of the gap between the urban and rural compulsory education in China lies in the unequal public resources possessed by urban and rural schools. In other words, the poverty of the rural compulsory education is, by nature, lack of resources. The distribution of public resources is executed by public and social policies; thus, policies are the leading factor producing the gap between urban and rural compulsory education.

Elite-oriented or city-oriented education policy serves as the direct inner factor deepening the disparity in education between urban and rural areas. For a long time, China's public policies have been so "city-oriented" that public resources are allocated unfairly and majority of high-quality education resources are concentrated in cities. This has already led to a serious unbalanced development in compulsory education and to a tremendous gap in conditions in schools - running and enrollment chances for the school-age children between rural and urban areas, which tend to be enlarged. The unbalanced development in compulsory education has not only blocked the realization of public interest and equity of compulsory education but also restricted the harmonious social and economic development between urban and rural areas. (Bao Chuanyou , 2006).

\section{B. Social Class:}

Connell \& Irving (1980) defined social class as: "by looking at class as a way of categorizing people, based on the reasoning that all societies are divided into groups that are hierarchically ordered in some way. This view frames class as social stratification. Different categories of people may be identified in terms of social attributes such as wealth, power and prestige".

Just like Australia, inequality is a simple fact of everyday life in China. Everyone recognizes that there are rich and poor and those in between; some people are born wealthy, some achieve wealth, and some have wealth thrust upon them, some people know that their children can never go to a private school while others cannot countenance their children going anywhere else. Patterns of inequality are based on the dimensions which include the amount of property one owns; the esteem or honor one receives; the ethnic group or racial group into which one is born; the income one receives; the rights and obligations one has; and the capacity to make decisions which affect other people's lives. When roles are allocated in a society in such a way that they are ranked above one another on such dimensions as these, the society is said to have a system of social stratification. (Waters, 1991)

A series of binary structure system is the institutional source of gap between urban and rural education in China. Due to the binary structure system, the people in city belong to the higher class. And the people in rural China belong to the lower class. They have lower income, little power, lower honor, little rights and little capacity to make decisions. China has a very unequal distribution of income, with a small group of people owning the bulk of the wealth. While the world average 
ratio of city vs countryside income is about 1.5 , in China it is 5.9 (official: 3.5 ). The central government is trying to levy higher and higher taxes on the high $(>20000 \mathrm{RMB} / \mathrm{year})$ incomes, but this is a sensitive area of policy-making and it goes very slowly. These income distribution and employment problems have a very complex social and political nature and cannot be changed overnight. (Wei Ji Ma, 2004)

Firstly, the household register system ( $\mathrm{Hu} \mathrm{Kou}$ ) is one of the most important binary structure systems. It has undergone changes many times from the beginning of the People's Republic of China to the 1990s. Step by step, it has dissimilated from its function of original household registrations to interest allocations. Social securities unfairly favor cities and city residents in all aspects such as the supply of daily necessities and produce necessities, education, employment, housing and labor security, etc., causing a strong barrier preventing villagers from migrating into cities. With the improvement of socialism market and the acceleration of urbanization in the 1990s, the reforms of the household register system have shown some new trends. The forbidding barrier between urban and rural areas has loosened, especially in small and middle cities, and the household register system has been cancelled, which has objectively promoted the flow of the villagers to cities and thus swept away the systematic barriers to narrow the gap between cities and rural areas. However, the long-standing basic pattern of binary structure based on the household register system cannot be broken in a short time. It still has a tremendous influence on China's social development (Wang Haiguang, 2003). As a result, a number of surplus populations have remained stagnant for a long time in the rural areas. On the one hand, rural families find their economic load doubled, facing great difficulties in affording for their children's education. On the other hand, the migrants from the countryside cannot obtain the same rights and securities as do the city dwellers just because they have no city domiciles. Their children have been stopped outside of the urban schools because of all kinds of charging fees such as sponsor fee, transfer fee, and school construction fee, which exceed their economic endurance so that their children have lagged behind the urban children from the beginning because they have no chance to get the same compulsory education. (Bao Chuanyou, 2003). Many migrants end up uneducated and unqualified, which is an increasing problem. Even rural students who have graduated from college sometimes have to go back to their hometown because of hu kou.

Secondly, due to the binary social structure of China, the social securities between the urban and rural areas make a great difference. Under the principle of "the urban public utilities funded by the state, the rural public utilities funded by the peasants," the city dwellers can enjoy social services provided by the government, such as housing, unemployment subsidies, medicare, cultural education, and transportation, etc., while the rural areas receive only occasional national relief and peasants' mutual aid and cooperation as their social securities. In fact, it is the peasants who take the burden of social securities, whose level is far less than that of the city dwellers.
The experiences of other countries imply that the social securities from workers to peasants have to undergo a long process, but it is still rare that the peasants in China became the backbone of the social securities and the gap between the urban and rural areas is so vast (Zhang Minjie, 2003).

\section{Habitus}

According to Daphne Meadmore, social class produces our identities from birth onwards through cultural knowledge, values, beliefs and affiliations as well as through economic circumstances. Our class and cultural identities are evident in our view of the world and our place in it. This identity formation has been termed "habitus" (Bourdieu 1984). How habitus is pivotal to the maintenance of social class is explained in the following:

Habitus is one's disposition, which influences the action that one takes; it can even be manifested in one's physical demeanor, such as the way one carries oneself or walks. It is generated by one's place in the social structure; by internalizing the social structure and one's place in it. One comes to determine what is possible and what is not possible for one's life and develops aspirations and practices accordingly. This internalization takes place during early childhood.... (Dumais 2002, p.46)

Students in rural areas in China have disadvantages in background. Their virtual schoolbags do not fit for the changing world. Let's take the migrant children education for an example; currently in China children of migrant workers do not have equal access to the urban public school system. On the one hand, good quality city schools rarely open their door to migrant children. On the other hand, for the limited number of migrant children who are admitted to public schools, there families struggle to pay the exorbitant amount of additional fees they are charged. This leaves migrant children with the options of attending private schools exclusively for migrant children (which in most cases are in very poor conditions), leaving their parents to attend hometown schools, or in the worst case scenario receiving no schooling at all. (Minmin Chen et al., 2006)

\section{Literacy and multiliteracy}

Peter Freebody and Allan Luke take the term "literacy" to refer to the extent to which people and communities can take part, fluently, effectively and critically, in the various text-and discourse-based events that characterize contemporary semiotic societies and economies. The circularity of this view is obvious. To be literate is to be an everyday participant in "literate" societies, themselves composed of a vast range of sites, locations and events that entail print, visual, digital and analogue media. "A literate society does not only involve actual reading and writing. Access to a literate society also entails being able to talk and listen, view and engage with various written, spoken, visual and aural texts in order to achieve social position, to actively reposition ourselves in the institutional fields that we live and work in". (Peter, et al. 2003). 
We are in the midst of one of the most dramatic technological revolution in history, which is changing everything in our life. This technological revolution center on information technology, is often interpreted as the beginning of a knowledge society, and therefore ascribes to education a central role in very aspect of life. We need a wide range of multiple literacies to deal with the exigencies of the cultural and technological revolution that we are currently involved in, ranging form computer literacy to multimedia literacy to new forms of cultural literacy. (Douglas Kellner, 2000).

The challenges for education today is to develop multiple literacies to empower students and citizens to use the new technologies to enhance their lives and to create a better culture and society based on respect for multicultural difference and aimed at fuller democratic participation of individuals and group largely excluded form wealth and power in the previous modern society. However, the great danger facing us is that the new technologies will increase the current inequalities based on class, gender, and racial division. So far, the privileged groups have had more direct and immediate access to the new technologies. It is therefore a challenge of education today to provide access to the new technologies, and to the literacies needed for competence, to excluded or oppressed individuals and groups in order to overcome some of the divisions and inequalities that have plagued contemporary societies during the entire modern age. (Douglas Kellner, 2000).

In China, compared with the urban students --the privileged group --, rural student, the unprivileged group, belong to the lower class, they have little power. There is still a big gap in compulsory education funds between urban and rural areas. In general, compared with other countries, the proportion of gross educational appropriation of the Chinese government that is used for compulsory education is much lower and is going downward, and also, the funds are not distributed equally between the urban and rural compulsory education. The government funds used for rural compulsory education were much less than that for urban compulsory education. Secondly, the tremendous gap between the urban and rural areas exists not only in the unbalanced distribution of compulsory education funds but also in teachers' levels: There is the gap in the educational attainment of full-time teachers between the urban and rural compulsory education; there is a gap in the number of part-time teachers between urban and rural compulsory education (Bao Chuanyou, 2006). All of these gaps brought about the divisions and inequalities in rural China, which can probably prevent the rural students, parents and teachers from the multiliteracies and access to modern knowledge society.

\section{Strategies for addressing the issue:}

A. Increase financial input to the underdeveloped rural areas.

According to www.china.org.cn, relatively poor western and rural areas where some 64 percent of China's population lives will receive priority in developing education over the next four years (beginning from 2003), with the Central
Government allocating 10 billion yuan (US\$1.2 billion) each year to the areas. This large allocation, at unprecedented levels, reflects the Central Government's determination to propel educational development in western areas so as to help advance the economy there. By 2007, students in rural and mountainous areas will be exempt from tuition, textbook expenses and fees for boarding schools, in an effort to prevent school dropouts. According to educational guidelines issued by the Ministry of Education on March 3, 2004 China has set a goal of ensuring the nine-year compulsory educational system covering at least 85 percent of the western area, basically eliminating youth illiteracy in the region.

\section{B. Strengthening the Reform on School Education in Rural Areas.}

Chinese government stressed on the active functions of rural schools in the new situations with fast development of rural economy. During the transition process from traditional agriculture production to modernized agriculture, the farmer are in urgent needs to master both literacy skills and scientific knowledge, which give rise to the higher requirements for all kinds of schools in rural areas. The importance and significance of rural education reform should be fully realized by governments at all levels and educational administrations. The main tasks of rural schools are to provide formal education to the young generation as well as non-formal education to raise the literacy level of rural population.

According to the Ministry of Education of China, education in rural areas has experienced fundamental changes and new progress made for the universalization of 9-year compulsory education. The central government initiated and implemented a series of projects and policies aiming to accelerate the development of education in rural areas. Through these projects and policies, condition for education provision in rural areas, especially in poverty-stricken areas, has been greatly improved and the difficulty of schooling for students from poor families has been further relieved. At the end of 2005, the State Council decided to reform the funding assurance system for compulsory education in the countryside, thus bringing rural compulsory education expenditure into the overall public funding assurance framework. This strategic measure will benefit millions of farmers and bring fundamental changes to compulsory education in rural areas.

\section{Conclusion}

Rural education is the focus of China's educational reform and development. The current rural education is developing under the national policy support and the guidance of the theory. But the overall situation is not optimistic. There are many problems in rural education to be solved. In order to promote the development of rural education in depth, we must involve in all aspects of the problems in rural education, and take various measures to push comprehensive reform. The real concern for education is providing equal and fair education for all, which requires all governments to provide the means to achieve this. 


\section{References}

[1] Bao Chuanyou, Policies for Compulsory Education Disparity Between Urban and Rural Areas in China, Higher Education Press and SpringerVerlag 2006

[2] Ben Wadham, Jason Pudsey, Ross Boyd, 2007, Culture and Education

[3] Bourdieu, P. (1984) Distinction: a social critique of the judgment of taste. Cambridge, MA: Harvard University. p 33

[4] Connell, R.W. \& Irving, T.H.(1980) Class Structure and Australian History: Documents, Narrative and Argument, Longman Cheshire, Melbourne.

[5] Daphne Meadmore, How do social class and education make the great divide? New Questions for Contemporary Teachers. P $74-75$

[6] Douglas Kellner, Multiple Literacies and Critical Pedagogies, New Paradigms, In (ed) Trifonas, P (2000) Revolutionary Pedagogies : Cultural Politics, Inshluty Education and the Discourse of Theory, Reutledge, London, PP 197 - 221.

[7] Dumais, S. (2002). Cultural capital, gender and school success: The role of habitus. Sociology of Education, 75 (jan.), 44-68.

[8] Emily Hannum, Children' Educaitonal Engagement in Rural China, 2007

[9] Fei Yan, Education problems with urban migratory children in China, Journal of Sociology and Social Welfare, Sept, 2005

[10] Hubert O. Brown, Comparative Education Review, vol. 30, No.3, August 1986, 373-387
[11] MA Wei-na, Occupation, Estate, Habitus: the Review of Educational Reflection of Teachers, International Forum on Teacher Education, Oct. 25-27, 2005 Shanghai, China

[12] MA Xue-qin, Problems and Countermeasures of Rural Education in China, Journal of Xichang College, Social Science Edition, 2010

[13] Minmin Chen, Ryan McCarthy, Akiko Nakano, Sal Scaturro, Increasing Educational Opportunities for Migrant Children in Beijing, May 8, 2006

[14] Peter Freebody and Allan Luke, Chapter 4 Literacy as Engaging with New Forms of Life: The Four Roles Model, The literacy Lexicon 2nd edition, Frenchs Forest, NSW: Pearson Education. Pp.3-15

[15] Waters, M \& Crook, R.(1991), sociology One, Longman Cheshire, Hong Kong.

[16] Wang Haiguang, The macroscopic analysis of formation and evolution of the contemporary Chinese household register system, Xinhua wenzhai (Xinhua digest), 2003, 298(10)

[17] Wang Dacheng, "Take the Road to Common Prosperity," Beijing Rewiew 26, No.39 (september 26, 1983):4

[18] Wei Ji Ma, Education in Urban and Rural China, Project Summary, October 2004

[19] Zhang Minjie A Study of Chinese Disadvantaged Groups), Beijing: Changchun chubanshe (Changchun Press), 2003. 